\title{
Contribution of Crown Lengthening to Optimize Aesthetics
}

\author{
Nissaf Daouahi ${ }^{1 *}$, Dalenda Hadyaoui², Zohra Nouira², Belhassen Harzalah², and Mounir Cherif ${ }^{2}$ \\ ${ }^{1}$ Deparmtent of fixed prosthodontics and esthetic dentistry, Faculty of dental medicine, Monastir, Tunisia \\ ${ }^{2}$ Research Laboratory of Occlusodontics and Ceramic Prostheses LR16ES15, Faculty of Dental Medicine, University of Monastir, Monastir, Tunisia
}

*Corresponding author: Nissaf Daouahi, Deparmtent of fixed prosthodontics and esthetic dentistry, Faculty of dental medicine, Monastir, Tunisia, Tel: +216 50725047; E-mail: nissafdaouahi@gmail.com

Received: 07 Aug, 2020 | Accepted: 20 Aug, 2020 | Published: 26 Aug, 2020

Citation: Daouahi N, Hadyaoui D, Nouira Z, Harzalah B, Cherif M (2020) Contribution of Crown Lengthening to Optimize Aesthetics. Int J Dent Oral Health 6(6): dx.doi.org/10.16966/2378-7090.334

Copyright: (c) 2020 Daouahi N, et al. This is an open-access article distributed under the terms of the Creative Commons Attribution License, which permits unrestricted use, distribution, and reproduction in any medium, provided the original author and source are credited.

\section{Abstract}

A 25 years old female patient presented with hidden smile and was bothered about the color discrepancy between maxillary anterior teeth. She was reporting dental pain in anterior region with mobility in central incisor.

Intra oral examination revealed severely discolored and endodontically treated left central incisor; Mobility was related to subgingival fracture of the teeth with violation of biological width. After removal of the fractured segment, periodontal probing showed involvement of biological width which needs to be re-established. It revealed also a thick gingival biotype; with gingival thickness of $2 \mathrm{~mm}$. Resin composite restorations, in proximal sides, were noticed on anterior teeth. Minor mal position and discrepancy between the 2 central incisors were, also, detected.

The treatment plan included crown lengthening in left central incsor, bleaching for both maxillary and mandibular arch and E max ceramic restortions, in maxillary incisors.

Keywords: Smile; Aesthetics; Central incisor; Crown lengthening; Ceramics

\section{Introduction}

As aesthetic demands have significantly increased to the point that less than optimal aesthetics are no longer acceptable. That's why the placement of aesthetically pleasing restorations, in the aesthetic zone, becomes a challenging goal. In fact, it is, strongly depending on the cooperation between different specialists including prosthodntics and periodontics. Aesthetic integration is, strongly, based on the harmony between pink and white tissues; in junction with the harmony between the smile and face [1-3].

One of the most important tasks in esthetic dentistry is the creation of harmonious proportions between the widths of maxillary anterior teeth when restoring or replacing them. The golden proportion concept has been offered as a basic concept of smile design theory.

Treatment considerations include the shape and the shade matching of the crown, interdental spacing, and esthetic desires which should be fulfilled. Careful rehabilitation plan and knowledge of morphological features of maxillary anterior teeth crowns, as influential factors for esthetic performance of the anterior dentition, are also necessary [4, 5]. Establishing correct proportions of anterior teeth depends also, according to Spear FM and Kokich VG [6] on optimizing gingival conditions and papilla levels and it is considered to be an important step in the process of establishing a correct position of maxillary anterior teeth.
To achieve correct gingival conditions in aesthetic zone, Crownlengthening surgery is one of the most common periodontal procedures used by periodontists according to American Academy of Periodontology [7]. It provides adequate supragingival tooth dimensions for proper restoration, and enhances aesthetics in case of gingival discrepancy. With reference to normal anatomy, it also provides the opportunity to recreate a correct Zenith location. Thus, its indications may include the presence of subgingival fracture and or pre-existing faulty subgingival margins requiring an increase in the length of the tooth, in order to place a restoration, in addition to biological width re-establishement $[7,8]$. Identifying each gingival biotype is important because of different healing tendencies. According to Olsson and Lindhe, the width thickness of the keratinized gingiva and incisor teeth shape determine the periodontal biotype which can affect the results of periodontal therapy [9-11].

The position of the lips, gingival tissue conditions, color, shape, and teeth position are Fundamental parameters for the management of an aesthetic smile. They should be performed when a prosthetic rehabilitation has been planned [1-3]. The central incisor should be the most dominant teeth displayed during the smile. According to Recent studies, similarities between professionals and non professionals regarding the dominance of central incisor in dental esthetic perception has been confirmed. A reduction of the width of lateral incisor about $0.5 \mathrm{~mm}$ can be unperceived. However, any reduction 
in an average central incisor length is not accepted [12,13]. When central incisor is endodontically treated and severely compromized, rehabilitation of the smile seems to be a challenging task. In fact, associating invasive and minimally invasive restorations in anterior teeth would be inadequate with correct light transmission because of differences in optical properties and behavior of materials. In addition, aesthetic restoration of the core poses problems because of limited possibilities of bonding techniques in reduced tissues level [14].

\section{Clinical Presentation}

This clinical report deals with aesthetic rehabilitation of a smile; where a central incisor was severely compromised and discolored. To fulfill aesthetic demands, bleaching in association with Crown lengthening and $\mathrm{E}$ max ceramic restorations were planned.

A 25 years old dental student patient presented to the department of aesthetic dentistry in dental clinic of Monastir. She was asking for improvement of the color of her teeth (Figure 1). In addition, she reports a mobility of her left central incisor (teeth\#21). A discrepancy between maxillary anterior teeth was detected [Figure 2]. She reports that she was under internal bleaching without satisfactory results. She was also suffering from dental moderate pain in this region.

Intra oral examination revealed severely discolored and endodonticaly treated left central incisor (Figure 3 ). The Mobility was related to subgingival fracture of the teeth with violation of biological width (Figure 4). After removal of the fractured part, periodental probing showed involvement of biological width with the need to be re-established. It revealed also a thick gingival biotype; with gingival thickness of $2 \mathrm{~mm}$. Resin composite restorations, in proximal sides, was noticed on anterior teeth. Minor mal position and discrepancy between the 2 central incisors were, also, detected.

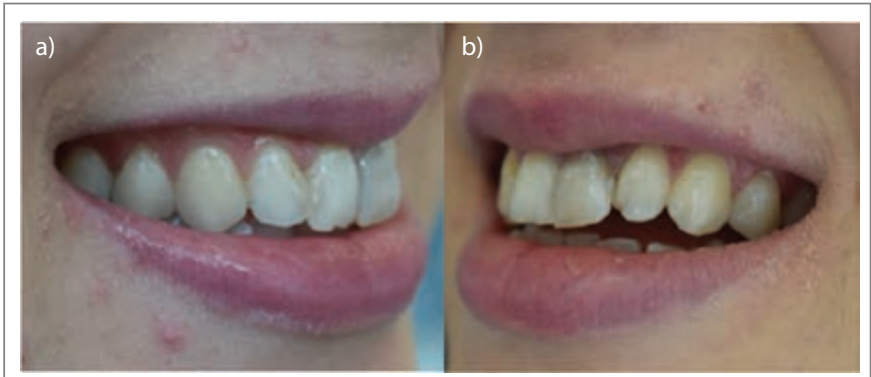

Figure 1a and b: Initial situation showing un esthetic smile

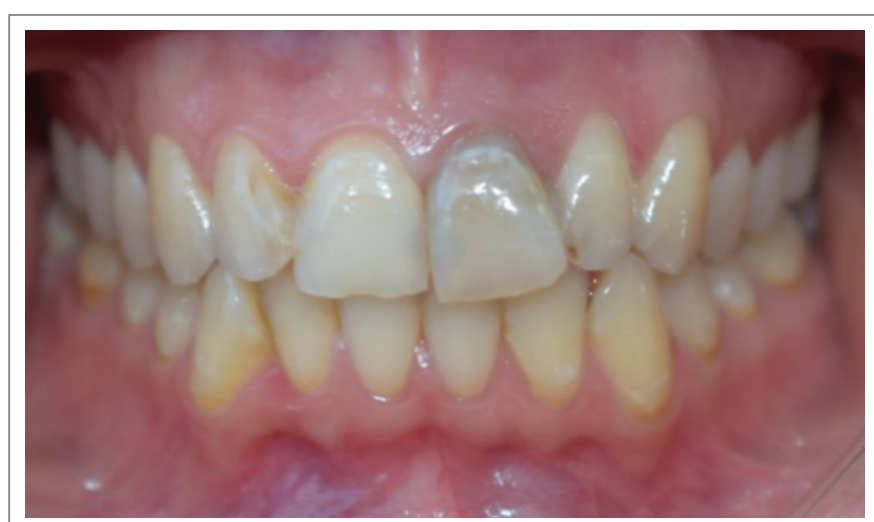

Figure 2: Front view showing discrepency between central incisors
Crown lengthening in left central incsor (Figure 5), bleaching for both maxillary and mandibular arch and Emax ceramic restorations, in maxillary incisors, were planned. Photographs were, firstly, taken using CANON 700D Cameras. In order to perform preliminary aesthetic analysis were performed. Diagnostic casts were waxed. The wax-up included all the desired elements in a smile design, from tooth proportion, axial inclination and gingival zenith, incisal arrangement and embrasures and gingival architecture.

A metallic post based provisional restoration was performed prior to surgical procedure and then modified according to new margins [Figure 6].

Aesthetic crown lengthening was performed to create adequate supragingival tooth dimensions for proper restoration and thus biological width re-establishment in right central incisor. A mucoperiosteal flap was elevated to gain access to the alveolar crest. A $1.5 \mathrm{~mm}$ Alveolar bone recontouring was judiciously performed to recreate a distance of $3 \mathrm{~mm}$, including the biological width, between the alveolar crest and the finishing line in buccal bone. In order to not expose the operation site to the oral environment and provide a safe healing process sutures were, finally, advocated after reapplication of the gingival [15]. Provisional restoration, which would guide the healing process, was relined and modified within the refined preparation according to new gingival margins. It was associated with a post for the retention. It was cemented with Eugenol Temporary Cement. The time span between the surgery and the final positioning of the gingival margins has been stated about 4 months which defines a period of stability.

In this case, bleaching was necessary prior to ceramic restorations. It reduced the discoloration which facilitates the use of ultra thin and translucent $\mathrm{E}$ max restorations. It was performed in the office using the Youtuel.

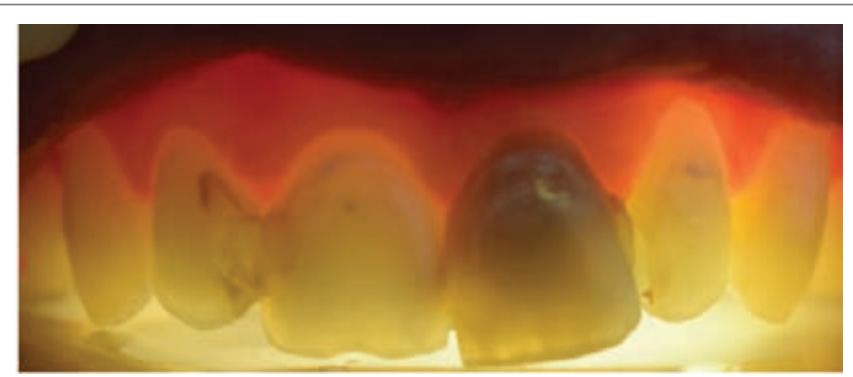

Figure 3: Severely discoloured and endodonticaly treated left central incisor

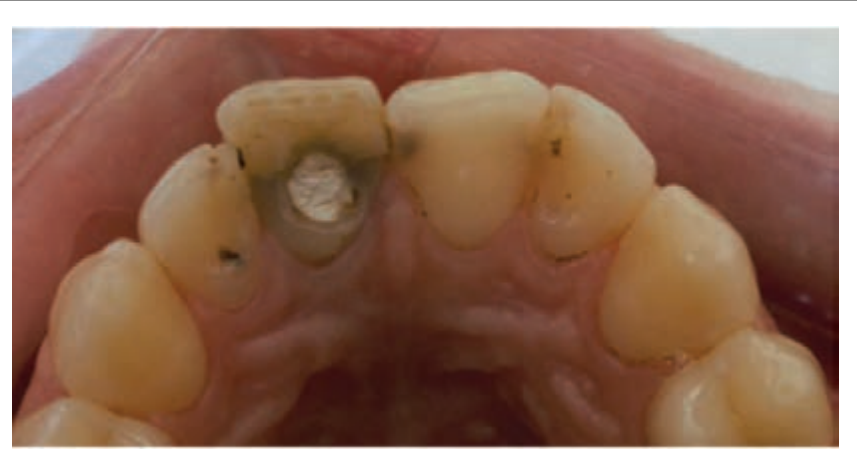

Figure 4: Fractured central incisor 


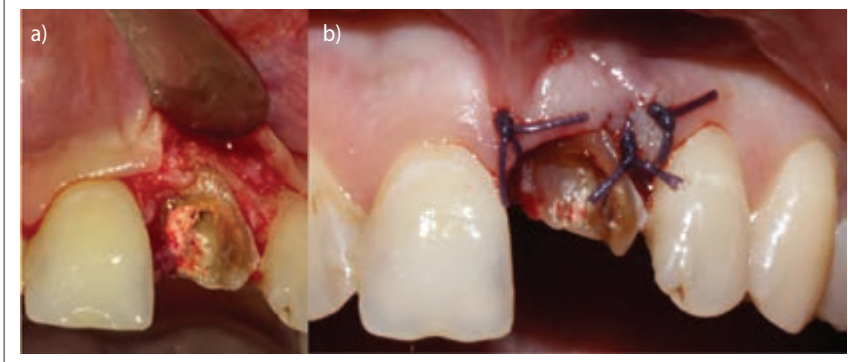

Figure 5a b: Crown lenthening
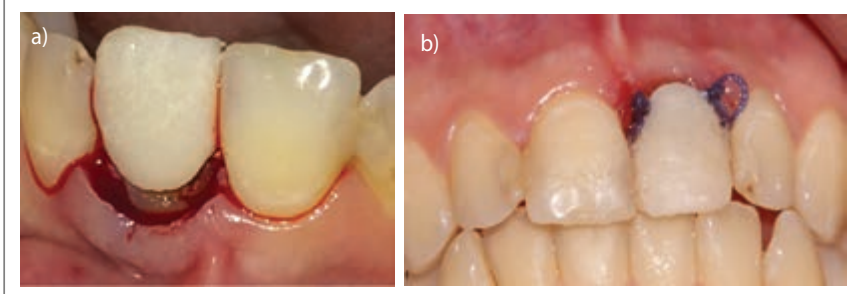

Figure 6a b: Temporisation

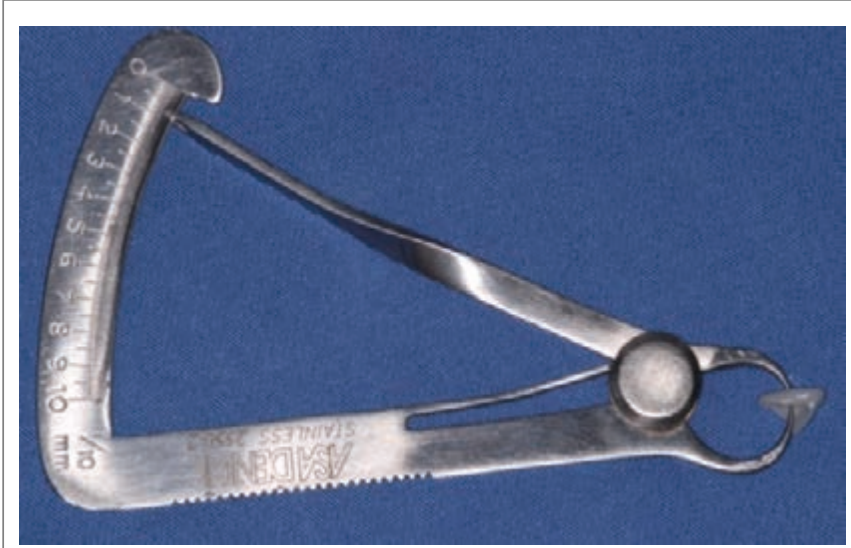

Figure 7: Minimally invasive restorations

After healing period and color stability after bleaching, the restoration of central incisor was performed using aesthetic post and core. The preparations were then e planned and $\mathrm{E}$ max ceramic restorations were performed using CAD/CAM technique (Figure 7). They were bonded using Variolink resin materiel (professional set, FL-9494 Schan/Liechtenstein) and according to according to the protocol described by Magne and Cascione (2006) protocol. Different shades of resin bonding materiel were selected according to the color of abutment in order to optimize the aesthetic result. Thanks to a well-planned multi-disciplinary approach, the result was esthetically acceptable and the patient was satisfied (Figures 8).

\section{Discussion}

Successful anterior restorations can be obtained when esthetic features and functional parameters are considered [16-18]. The ratio of Width-to-height $(\mathrm{W} / \mathrm{H})$ is reliable tool which guides clinicians to provide the patient a suitable dental appearance [19].

Tapered incisors seem to be the most attractive for both male and female more than square and triangular. This fact was confirmed by a

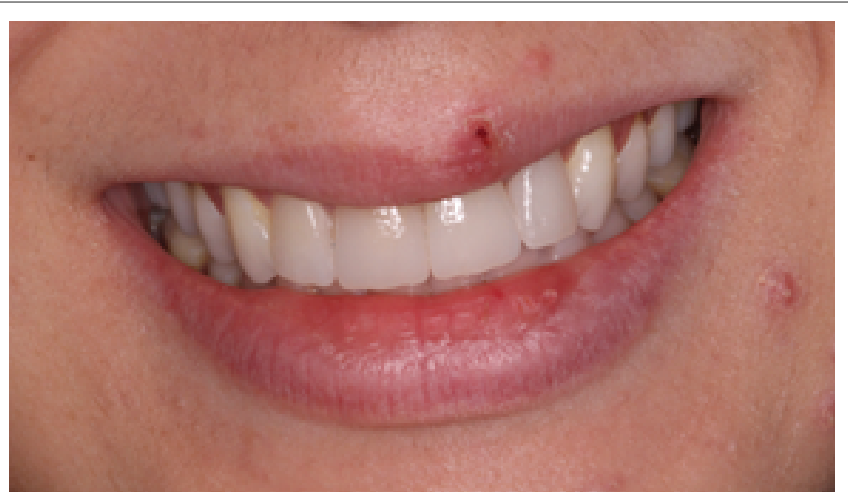

Figure 8: Final result.

recent systematic review dealing with the issue of lay preferences for dentogingiva esthetic parameters [13]. The position of incisal edge of the central incisor is of concern in esthetic perception; it should be parallel to bipopular plan. Vertical asymmetries as small as 0.6 were perceived as unacceptable according to recent study [14].

To match the optical properties of natural teeth with those of artificial teeth is a significant challenge in aesthetic dentistry [20,21]. Chaiyabutr Y, et al. [22] worked on the factors influencing the final esthetic result; He confirmed that the underlying tooth abutment color, cement color, and ceramic thickness influence significantly the resulting optical color of a CAD/CAM glass-ceramic lithium disilicatereinforced crown. According to his study, changing the underlying color of the abutment tooth from a lighter to a darker conduct to differences in light transmission. In addition, translucent cement should not be used for cementing crowns with a ceramic thickness of $1.5 \mathrm{~mm}$; because of clinically unacceptable color change range.

Others suggest the application of different color luting composites for adjusting the resultant color as Manufacturers have introduced several adhesive systems for ultra thin restorations which includes various colors of luting composites and the corresponding try-in pastes. High agreement of correspondence between try-in paste and the corresponding luting composite has also been reported in one hand [23-25]. In the other hand, a clinically significant color differences between a try-in paste and the luting composite of the same shade was noted according to AL Ghazali N, et al. [26]. The American college of prosthodontists confirmed in 2013, via the study conducted on Laboratory of Oral Biomedical Engineering of Ministry of Education in the School and Hospital of Stomatology at Wuhan University, that color agreement of try-in pastes and the corresponding luting composites is not always achieved, especially for the application of darker and more opaque agents [27].

To obtain aesthetically accepted result, it is also necessary to create healthy periodontal conditions via optimal soft tissues profile around restorations.

However, conditions are in some clinical situations, including deep preparation margins and fracture, unfavorable for successful restorative procedures. In such situations, to improve the anatomical conditions surgical lengthening of the conical crown is indicated. Well-defined preparation margins, permitting a high control of the marginal fit and optimal access for daily plaque control, are highly recommended. In Addition Sufficient length of the clinical crown is required for optimal retention of the restoration [28-33]. 


\section{Conclusion}

Matching the optical properties of natural teeth with those of artificial teeth is a significant challenge in aesthetic dentistry. Creating healthy periodontal conditions around aesthetic restorations is also an important factor to obtain aesthetically accepted result via optimal soft tissues profile around restorations.

\section{References}

1. Claman L, Alfaro MA, Mercados A (2003) An interdisciplinary approach for improved esthetic results in the anterior. J Prosth Dent 89: 1-5.

2. Simon Z (2010) Challenge in achieving gingival harmony. J Calif Dent Assoc 38: 583-590.

3. Ahmad I (2005) Anterior dental aesthetics: Gingival perspective. Br Dent J 199: 195-202.

4. Pinho T, Neves M, Alves C (2012) Multidisciplinary management including periodontics, orthodontics, implants, and prosthetics for an adult. Am J Orthod Dentofacial Orthop 142: 235-245.

5. Dundar M, Gungor MA, Cal E (2003) Multidisciplinary approach to restoring anterior maxillary partial edentulous area using an IPS Empress 2 fixed partial denture: A clinical report. J Prosthetic Dent 89: 327-330.

6. Spear FM, Kokich VG (2007) A multidisciplinary approach to esthetic dentistry. Dent Clin North Am 51: 487-505.

7. American Academy of Periodontology (2003) Practice Profile Survey: Characteristics and Trends in Private Periodontal Practice. Chicago: American Academy of Periodontology 2004.

8. Perez JR, Smukler H, Nunn ME (2007) Clinical evaluation of the supraosseous gingivae before and after crown lengthening. J Periodontol 78: 1023-1030.

9. Fletcher $P$ (2011) Biologic rationale of esthetic crown lengthening using innovative proportion gauges. Int J Periodontics Restorative Dent 31: 523-532.

10. Bednarz W (2011) The thickness of periodontal soft tissues ultrasonic examination-Current possibilities and perspectives. Dent Med Probl 48: 303-310.

11. Sin Y-W, Chang H-Y, Yun WH, Jeong S-N, Pi S-H, et al. (2013) Association of gingival biotype with the results of scaling and root planing. J Periondontal Implant Sci 43: 283-290.

12. Shetty S, Pitti V, Babu CIS, Kumar GPS, Jnanadev K (2011) To evaluate the validity of recurring esthetic dental proportion in natural dentition. J Conserv Dent 14: 314-317.

13. Del Monte S, Afrashtehfar KI, Emami E, Abi Nader S, Tamimi F (2017) Lay preferences for dentogingival esthetic parameters: A systematic review. J Prosthetic Dent 118: 717-724.

14. Machado AW, Moon W, Gandini LG Jr (2013) Influence of maxillary incisor edge asymmetries on the perception of smile esthetics among orthodontists and laypersons. Am J Orthod Dentofacial Orthop 143: 658-664.

15. Huynh G, Lang BN (2007) Surgical lengthening of the clinical crown: a periodontal concept for reconstructive dentistry. Periodontology 3: 193-201.
16. De Andrade OS, Hirata R, Celestrino M, Seto M, Siqueira $S \mathrm{Jr}$, et al. (2012) Ultimate ceramic veneer: a laboratory-guided preparation technique for minimally invasive laminate veneers. J Calif Dent Assoc 40: 489-494.

17. Radz GM (2011) Minimum thickness anterior porcelain restorations. Dental Clinics of North America 55: 353-370.

18. Vichi A, Louca C, Corciolani G, Ferrari M (2011) Color related to ceramic and zirconia restorations: A review. Dent Mater 27: 97-108.

19. Sarver DM (2004) Principles of cosmetic dentistry in orthodontics: Part 1. Shape and proportionality of anterior teeth. Am J Orthod Dentofacial Orthop 126: 749-753.

20. Van Noort R (2007) Introduction to dental materials. $2^{\text {nd }}$ Edition, St Louis, Elsevier 247-50. 21.

21. McLean JW, Hubbard JR, Kedge MI (1979) Science and art of dental ceramics. Quintessence, Chicago 333.

22. Chaiyabutr $Y$, Kois JC, Lebeau D, Nunokawa G (2011) Effect of abutment tooth color, cement color, and ceramic thickness on the resulting optical color of a CAD/CAM glass-ceramic lithium disilicatereinforced crown. J Prosthet Dent 105: 83-90.

23. Chadwick RG, Mccabe JF, Carrick TE (2008) Rheological properties of veneer trial pastes relevant to clinical success. Br Dent J 204: E11.

24. Xing W, Jiang T, Ma X, Liang S, Wang Z, et al. (2010) Evaluation of the esthetic effect of resin cements and try-in pastes on ceromer veneers. J Dent 38: e87-e94.

25. Wang X, Powers JM (1999) Color differences between a resin cement and try-in paste. Zhonghua Kou Qiang Yi Xue Za Zhi 34: 58-59.

26. AL Ghazali N, Laukner J, Burnside G, Jarad FD, Smith PW, et al. (2010) An investigation into the effect of try-in pastes, uncured and cured resin cements on the overall color of ceramic veneer restorations: an in vitro study. J Dent 38: e78-e86.

27. Binting $X u, C h e n ~ X, L i, R$, Wang $Y$, Li Q (2014) Agreement of try-in pastes and the corresponding luting composites on the final color of ceramic veneers. J Prosthodont 23: 308-312.

28. Baima RF (1986) Extension of clinical crown length. J Prosthet Dent 55: 547-551.

29. Bragger, U, Pasquali L, Kornman KS (1988) Remodelling of interdental alveolar bone after periodontal flap procedures assessed by means of computer-assisted densitometric image analysis (CADIA). J Clin Periodontol 15: 558-564.

30. Bragger U, Lang $\mathrm{N}$, Chirugische $\mathrm{P}$ (1988) Verlangerung der klinischen Krone, Schweizerische Monatsschrift filr Zahnmedizin 98: 644-651.

31. Lanza A, Di Francesco F, De Marco G, Femiano F, Itro A (2017) Clinical Application of the PES/WES Index on Natural Teeth: Case Report and Literature Review. Case Rep Dent.

32. Elias AC, Sheiham A (1998) The relationship between satisfaction with mouth and number and position of teeth. J Oral Rehabil 25: 649-661.

33. Levin El (1978) Dental esthetics and the golden proportion. J Prosthet Dent 40: 244-252. 